\title{
O ensino das expressões idiomáticas em língua espanhola e suas equivalências em língua portuguesa
}

\author{
Lucielena Mendonça de LIMA \\ Universidade Federal de Goiás \\ llima@letras.ufg.br
Maria Luisa ORTIZ ÁLVAREZ
Universidade de Brasília
marialuisa.ortiz@gmail.com

\begin{abstract}
Resumo
Quando aprendemos uma língua não podemos nos esquecer de que aprendemos também a maneira de ver o mundo e os costumes da sociedade que a fala, ou seja, a sua visão de mundo manifestada através das escolhas linguísticas. Daí que os mal-entendidos dos alunos de Espanhol como Língua Estrangeiras (E/LE) são, muitas vezes, resultado do desconhecimento tanto dos fatos linguísticos como dos culturais. As expressões idiomáticas, além de serem um ponto de partida de possíveis aulas, traduzem a cultura, pois sua origem normalmente é popular e ancestral. Neste artigo, discutimos sua importância para desenvolver a competência comunicativa dos aprendizes e também apresentamos estratégias com o objetivo de ensiná-las.
\end{abstract}

Palavras-chave: estratégias, expressão idiomática, língua espanhola

\begin{abstract}
When we learn a language, we should not forget that we are also learning the habits and the way that the society which speaks that language sees the world, that is, its vision of the world expressed through liguistic choices. This is the reason why Spanish as Foreign Language students' misunderstadings are commonly the consequence of ignoring both linguistic and cultural facts. Idioms are not only a startig point for possible lessons, but they also translate the culture, for their origin is commonly popular and ancestral. In this paper we discuss their importance for the development of students' communicative abilities. We also introduce strategies that can be used to teach them.
\end{abstract}

Keywords: teaching strategies, idioms, Spanish 


\section{Introdução}

As expressões idiomáticas caracterizam-se por serem elementos fraseológicos que, segundo Varela e Kubarth (1996, p. X$\mathrm{XI}$ ), obedecem a dois critérios: o da estabilidade ou fixação, isto é, são estruturas formais estáveis ou fixas e o da idiomaticidade, ou seja, estão ligadas, com exclusividade, a uma língua determinada e às vezes perdem o valor histórico e cultural. Vemos assim a importância de estudá-las em contextos significativos que nos orientem sobre seu uso adequado em situações específicas. Posto que, como afirma VázquezAyora (1977, p. 320),

a 'linguagem figurada' é tão extensa que abarca todos os níveis da língua e, [...] é a característica que compartilham a 'língua comum' e a 'literária'. A fala comum é fala coloquial, e todos os níveis, sejam ou não literários, se caracterizam pela presença constante de visão figurada e, repetimos, não nos referimos unicamente às chamadas figuras literárias, mas também a uma grande variedade de expressões que ainda não não foram classificadas como tais ${ }^{1}$. (Grifos do autor)

Casares (1992, p. 218-219), quando expõe as prováveis causas que motivaram a proliferação das expressões idiomáticas em espanhol, afirma que são de caráter social e linguístico. Sobre o primeiro, nos explica que

é sabido que nenhuma das línguas modernas de cultura carece delas e que, portanto, a questão poderia ser estudada de um ponto de vista geral; porém fora de que nestes momentos só nos interessam as expressões idiomáticas do castelhano, existe o fato de que em nenhum país estas

\footnotetext{
${ }^{1}$ Tradução nossa: el 'lenguaje figurado' es tan extenso que abarca todos los niveles de lengua y, [...] es la característica que comparten la 'lengua común' y la 'literaria'. El habla común, el habla coloquial, y todos los niveles, sean o no literarios, se caracterizan por la presencia constante de visión figurada y, repetimos, no nos referimos únicamente a las llamadas figuras literarias, sino a una gran variedad de expresiones que todavía no se han clasificadas como tales.
} 
fórmulas expressivas tiveram o desenvolvimento quase anormal que observamos em nossa pátria [Espanha], nem tiveram em parte alguma o predicamento em que tiveram os grandes escritores de nosso Século de Ouro. [...] a expressão idiomática, como a comparação atrevida e feliz que logo, transformada em metáfora (sem intervenção literária), se incorpora à língua, são criações populares baseadas na fertilidade e vivacidade das associações imaginativas; criações populares, não porque o povo amorfo as inventou, mas porque este possuia, no momento oportuno, a receptividade psicológica conveniente para que prosperassem certos achados individuais, como prospera um germe dado em seu caldo de cultivo específico ${ }^{2}$.

Sobre o conceito popular, Marco (1977, p. 48-50) afirma que, “o certo é que o termo 'popular' esconde uma carga de diversos significados e muitas vezes uma determinada posição perante a literatura e inclusive um determinado conceito do mundo. [...] A literatura popular espanhola é radicalmente conservadora de fundo e de formas"3. Portanto, a cultura é capaz de identificar os indivíduos por "seus modos de agir, vestir, caminhar, comer, sem mencionar a evidência das diferenças lingüísticas, o fato de mais imediata observação empírica", de acordo com Laraia (1993, p. 68).

\footnotetext{
${ }^{2}$ Sabido es que no carece de ellas ninguna de las modernas lenguas de cultura y que, por tanto, la cuestión podría estudiarse desde un punto de vista general; pero fuera de que en estos momentos sólo nos interesan los modismos del castellano, existe el hecho de que en ningún país han tenido estas fórmulas expresivas el desarrollo casi anormal que observamos en nuestra patria [Espanha], ni han logrado en parte alguna el predicamento en que las tuvieron los grandes escritores de nuestro Siglo de Oro. [...] el modismo, como la comparación atrevida y feliz que luego, transformada en metáfora (sin intervención literaria), se incorpora a la lengua, son creaciones populares basadas en la fertilidad y viveza de las asociaciones imaginativas; creaciones populares, no porque las haya inventado el pueblo amorfo, sino porque éste poseía, en el momento oportuno, la receptividad psicológica conveniente para que prosperasen ciertos hallagos individuales, como prospera un germen dado en su caldo de cultivo específico.

${ }^{3}$ Lo cierto es que el término 'popular' esconde una carga de diversos significados y muchas veces una determinada posición ante la literatura e incluso un determinado concepto del mundo. [...] La literatura popular española es radicalmente conservadora de fondo y de formas.
} 
Logo, podemos supor que para um falante não nativo, o uso de maneira consciente e espontânea das expressões idiomáticas convertese em uma dificuldade superada somente com um excelente nível linguístico e com um curso de imersão, ou seja, passar um determinado tempo estudando in situ a língua, já que esta é uma das manifestações linguístico-culturais populares. Assim, nos processos de ensinoaprendizagem de E/LE transpassam-se também as visões de mundo de professores e alunos, tendo em vista que a língua serve para comunicar os fatos lingüísticos e os extralingüísticos, pois fala do mundo e da sua realidade conhecida. Vemos, assim, que a língua é uma manifestação cultural que adquirimos simultaneamente com a língua que estudamos.

Além disso, não podemos deixar de lembrar que a realidade que uma língua configura de uma maneira, pode configurá-la de uma outra maneira diferente. Por isso a importância de aproveitar as expressões idiomáticas como temas para desenvolver nas aulas de E/LE, para que os alunos possam conseguir um nível de discernimento parecido com este que nos sugere Casares (1992, p. 225) ao afirmar que "o uso da expressão idiomática, quando é feito de maneira consciente, se opera por aceitação ou eliminação do que espontaneamente surge em nosso espírito, e não porque vamos buscála no depósito do nosso léxico latente" ${ }^{\text {. }}$.

Sobre a necessidade e utilidade do ensino das expressões idiomáticas, podemos afirmar que são muitas as vantagens advindas. Em primeiro lugar, melhora de maneira evidente a compreensão do aluno, tanto oral como escrita, já que as expressões idiomáticas são opacas em muitos casos, ou seja, o significado é metafórico e por is so podem constituir um sério obstáculo para a interpretação e, consequentemente, estabelecer a comunicação em uma conversação coloquial. Além disso, é necessário, também, que o professor dedique a elas uma atenção especial, tendo em vista que nem todas aparecem nos dicionários. A estabilidade, ou a estrutura fixa, deste tipo de expressões, da mesma maneira que ocorre com as expressões institucionalizadas ou convencionais que têm o significado literal ou

\footnotetext{
${ }^{4}$ El empleo del modismo, cuando se hace de manera consciente, se opera por aceptación o eliminación del que espontáneamente surge en nuestro espíritu, y no porque vayamos a buscarlos al almacén de nuestro léxico latente.
} 
transparente, facilita sua memorização ou, pelo menos, seu reconhecimento quando apareçam em outros contextos.

Em segundo lugar, seu ensino, também, se traduz em uma melhora da expressão oral e escrita porque, ao ser unidades lexicalizadas, uma vez memorizadas são utilizadas como um bloco linguístico, de forma espontânea, agilizando assim a comunicação; visto que o aluno não deve compor em cada caso uma nova oração mediante a mera justaposição de elementos, mas sim recorrer aos blocos mais extensos. Este fato condicionará a metodologia, pois nos veremos obrigados a realizar exercícios para a compreensão dos seus significados.

Em terceiro lugar, não podemos desconsiderar o inegável legado cultural relacionado a algumas expressões idiomáticas: este pode ser um bom ponto de partida para explicar comportamentos, atitudes, formas de vida, modos de pensar e, assim, promover um aprendizado intercultural que busca o respeito pelas culturas distintas. Como exemplo, pensemos nas expressões relacionadas com a religião como: hacerlo como Dios manda, hablar en cristiano, ser un calvario, ser una cruz, ou em outras relacionadas com o mundo dos touros: echar un capote, entrar a matar, cambiar de tercio, dar la puntilla etc.

Em quarto lugar, o ensino das expressões idiomáticas corresponde a uma necessidade real dos alunos, pois eles são os primeiros a constatar a necessidade de aprender estes blocos ou unidades linguísticas compostas por mais de uma palavra. Considerando que estas expressões são universais, isto é, existem em todas as línguas naturais, a principal vantagem é que, com seu ensino, evitamos muitos erros de transferência e interferência da língua materna (LM), posto que ao querer usá-las em língua espanhola, o mais provável é que os alunos as traduzam literalmente, da LM para E/LE. Portanto, é lógico pensar que tão logo obtenha um grau de competência linguística, deseje incorporar ao seu léxico ativo estas unidades.

Por último, é sabido por todos que estes tipos de expressões são de vital importância para aquelas pessoas que estão interessadas em fazer exames de proficiência como, por exemplo, Certificado de Proficiência em Língua Espanhola (DELE) nos níveis: Inicial, Básico e Superior, nos quais são incluídas essas unidades fraseológicas. 


\section{Estratégias para ensinar as expressões idiomáticas}

Merecem atenção especial os distintos critérios utilizados para classificar este tipo de expressões, já que uma poderosa estratégia, para facilitar a memorização, consiste em ordená-las em diferentes grupos. A seguir, examinamos alguns dos mais utilizados, junto com uma análise crítica de suas vantagens e inconvenientes. Vários linguistas se dedicaram a definir e classificar as expressões idiomáticas, citando apenas alguns deles, Higueras (1997); Sánchez Lobato, (1999); McCarthy e O’Dell (1994); Tagnin (2005); Varela e Kubarth, (1996); Xatara (2001), entre outros.

McCarthy e O’Dell (1994) distinguem três c0ritérios para classificar as expressões idiomáticas e sugerem ao aluno que os utilize para anotar coerentemente as expressões que for aprendendo. Em primeiro lugar, mencionam o critério gramatical, que consiste, por exemplo, em separar as expressões que contém verbos seguidos de um complemento direto (dar la espalda, dar la puntilla, dar la cara etc.), das que têm verbos acompanhados por um sintagma preposicional (salir por la tangente, salir por peteneras, salir por los cerros de Úbeda etc.).

O segundo critério propõe agrupar as expressões idiomáticas pelo seu significado, isto é, associadas a uma função comunicativa. Por exemplo, anotar e estudar juntas as expressões para descrever o caráter das pessoas ou as que servem para descrevê-las fisicamente.

Por último, o terceiro tipo se baseia em uma palabra-chave, por exemplo: dar verde, ao redor da qual são anotadas todas as expressões das que forma parte (dar coba, dar la lata, ser un viejo verde etc.)

Podemos acrescentar também outros dois, a partir de seu aparecimento nos materiais publicados para o ensino de E/LE e de nossa própria experiência: a classificação pelos campos semánticos, ou seja, as expressões que têm alguma palavra pertencente a um campo determinado como, por exemplo, as partes do corpo (dar la espalda, tomar el pelo, hablar por los codos, etc.) ou por temas como o trabalho (trabajar de sol a sol, ser trabajo de chinos, trabajar por amor al arte etc.)

Nem todos os critérios nos parecem adequados: o critério gramatical, por exemplo, parece mais próprio para um gramático do que para um aluno ou professor de línguas estrangeiras. Se em muitos 
casos, temos dificuldades para que o aluno reconheça um verbo ou um adjetivo, será mais complicado introduzir um conceito novo como o de complemento direto ou indireto.

O critério de número dois - reuni-las pelo seu significado pode ser muito mais eficaz, visto que são associadas a uma função comunicativa concreta, que podemos praticar depois com atividades de expressão oral e escrita, o que ajuda a memorizá-las e aprender a utilizá-las em seu contexto adequado.

O critério de número três - agrupá-las por uma palavra-chave - é talvez o mais empregado nos manuais de ensino de E/LE, porém não é por isso que seja o mais útil nem o mais acertado, já que muitas vezes serve somente para criar uma inevitável confusão no aluno.

Em nossa opinião, agrupar as expressões por uma palavrachave pode ser válido do ponto de vista lexicográfico, mas é um falso critério do ponto de vista didático, por várias razões:

a) não tem uma base psicolinguística, isto é, não faz parte dos processos mentais que usamos para armazenar e recuperar o léxico, já que não favorecem as associações de cada palavra-chave com outras que sirvam para a mesma função comunicativa;

b) origina confusão entre umas expressões e outras porque na maioria dos casos não aparecem os contextos de uso;

c) dificulta sua utilização em exercícios comunicativos, tendo em vista que cada expressão idiomática se associa a uma função comunicativa distinta; por conseguinte, não as memorizamos muito facilmente.

O quarto critério assinala a possibilidade de agrupá-las por campos semánticos; também aqui há que fazer uma ressalva: sempre que as expressões agrupadas, a partir deste criério, não sejam semanticamente opacas, é mais coerente ensiná-las juntas, porém quando tenham perdido seu significado literal, essa agrupação é pouco rentável, do ponto de vista didático. Vejamos um exemplo: parece lógico pensar que se desejamos que nossos alunos entendam ou consigam usar uma expressão como "me importa um pepino", é melhor que a associem com "me da igual, no me importa, no me preocupa", e não com as expressões que contenham palavras com as 
que se associa paradigmaticamente "pepino", por exemplo, "ponerse como un tomate, estar más fresco que una lechuga" etc.

No entanto, infelizmente, nos manuais didáticos, observamos um uso indiscriminado deste tipo de critério e poucas vezes as associam às funções comunicativas. Nesse sentido, encontramos inúmeros exemplos deste tipo: expressões idiomáticas com os nomes das partes do corpo, alimentos, cores etc. Além disso, alguns dos inconvenientes antes destacados são aplicáveis aqui também: podem surgir confusões e, por outro lado, é difícil praticá-las em exercícios do tipo "preencher lacunas".

A quinta sugestão - utilizar o critério temático - nos parece a mais plausível, visto que as expressões idiomáticas, bem como as convencionalizadas, são aprendidas a partir de um tema, independentemente de ser opacas ou transparentes. Dessa forma, se realizarmos atividades com léxico a partir de temas como "el trabajo, la casa, la gente, la ciudad" etc, poderiamos oferecer diferentes tipos de unidades lexicais e, ainda que o aluno não consiga distinguir conceitualmente umas das outras, poderá expressar-se sobre o tema, porque lhe proporcionamos os recursos léxicos suficientes.

A partir de nossa experiência em sala de aula, chegamos à conclusão de que determinados critérios de classificação não são muito eficazes, se esperamos que os alunos consigam memorizar os significados das expressões e, principalmente, usá-las nos atos de fala adequados.

Assim, propomos o critério dos campos semânticos destacando as funções comunicativas para as quais servem determinadas expressões:

a) Descrever fisicamente as pessoas: estar en los huesos, estar/ser más viejo que Matusalén, ser más fuerte que un roble, ser una cacatúa, no ver tres en un burro (a tres pasos) etc.

b) Descrever psicologicamente as pessoas: ser mala pieza, ser de armas tomar, ser un alma de Dios, darse de aires, ser más bueno que el pan, ser más bruto que un arado, ser más agarrado que un pasamanos, ser una fiera, ser una bestia, ser un viejo verde, ser un borrego (burro, buitre, besugo, ganso, gorila, rata, mosquita muerta, gallina etc). 
c) Descrever os estados anímicos das pessoas: estar hasta la coronilla, estar de juerga, estar orgulloso de, estar hecho una fiera, estar a la expectativa, estar chiflado, estar de malas, estar más contento que unas castañuelas, estar como una seda, estar como una flauta/cabra/regadera, estar como una seda etc.

d) Fazer comparações: ser (como) uña y carne, ser más lento que el caballo del malo, ser/estar como perro y gato, estar blanco como el papel/la pared, ser/estar más negro que el azabachelel betún/el tizón/el pez, etc.

e) Descrever as reações das pessoas ante determinadas situações, problemas etc: ponerse colorado, poner pies en polvorosa, poner en ridículo, poner por encima, poner en claro, ponerse al corrienteldía, poner en tela de juicio, tener ganas, tener en cuenta, meterse alguien en su concha, salirse por la tangente, estar verdelamarillo/ tísico de envidia, estar/ponerse rojo como un tomate/un pimiento/un semáforo etc.

f) Descrever o comportamento das pessoas: dar gato por liebre, dar la lata, darse aires, hacer castillos en el aire, hacer la cama a alguien, hacer la pascua a alguien, hacer la rosca a alguien, hacer borrón y cuenta nueva etc.

g) Descrever as coisas, situações, lugares, etc: ser el colmo, estar todo patas arriba etc.

Xatara (2001) propõe uma classificação a partir do grau de dificuldade de aprendizagem. Embora o uso dessas unidades idiomáticas "não esteja restrito a níveis de aprendizagem, sua aquisição pode ser facilitada se os diferentes graus de dificuldades de aprendizagem forem considerados" (XATARA, 2001, p. 53). O modelo de classificação das expressões idiomáticas proposto por esta autora, e que vamos a fazer uso em nossa análise, se refere à língua francesa, porém é aplicável a qualquer outra língua, no nosso caso, ensino de E/LE. São sugestões nossas as equivalências em português citadas ao longo do texto.

As expressões que se incluem no grau de dificuldade 1 são aquelas que "têm equivalência idiomática e literal na língua portuguesa” (XATARA, 2001, p. 53). Supõe-se que são as unidades 
fraseológicas de mais fácil ensino e aprendizagem. Como exemplos, temos: llegar a las tantas - chegar às tantas; llover a cántaros chover a cântaros; darl pegar un toque - dar um toque. Porém, notamos que esta mesma expressão em português, além do sentido de telefonar para alguém, pode ser também dar um sinal ou aviso.

Pertencem ao grau 2 de dificuldade as expressões que possuem "equivalência idiomática semelhante no português", assim, a equivalência léxica que existe se aproxima, "sem alteração da estrutura, do valor, do efeito comunicativo ou do nível de linguagem" em espanhol (XATARA, 2001, p. 54): ponerse como una sopa - ficar ensopado; estar de humor de perros - estar com um humor de cão.

No grau 3 de dificuldade se incluem aquelas que também possuem expressões metafóricas equivalentes, "mas de estrutura sintática e/o unidades lexicais diferentes" em espanhol (XATARA, 2001, p. 54): estar por las nubes - custar os olhos da cara ou estar pela hora da norte; hacer pellas - matar aula; aprobar por los pelos - passar raspando ou passar por um triz.

Classifica-se no nível 4 de dificuldade a expressão da língua espanhola "sem equivalência idiomática na língua portuguesa" (XATARA, 2001 p. 44-45), ou, ao contrário, do português ao espanhol, assim é necessário fazer uma paráfrase para explicar o significado, ou traduzir o significado de forma literal. Um exemplo a ser comentado é a expressão salir de marcha que é, literalmente, sair para divertir-se. Porém, na Espanha, essa diversão consiste em ir de bar em bar sem permanecer muito tempo em nenhum deles. A expressão ir para a balada recupera em parte o sentido, porém não é costume ou comportamento cultural do brasileiro, principalmente nas grandes cidades, por motivo de segurança, circular a pé como fazem os espanhóis em Madri, por exemplo.

\section{Estratégia de ensino e equivalências semântico- pragmáticas}

No âmbito dos estudos da tradução (BARBOSA, 1990; VÁZQUEZ-AYORA, 1977), o princípio do efeito equivalente prevê que o texto traduzido deva despertar no leitor o mesmo efeito que foi 
provocado no leitor do texto original. Portanto, a tradução não deve ser feita de forma literal, porque o texto traduzido poderia "ter significado diverso do original; não ter significado; ser estruturalmente impossível; não ter correspondência no contexto cultural e ter correspondência, mas não no mesmo registro", como afirmam Vinay e Darbelnet (1957, apud BARBOSA,1990, p. 24) autores do método da tradução oblíqua. Por isso, para solucionar estas dificuldades, estes autores elaboraram quatro procedimentos: transposição, modulação, adaptação e equivalência. Este último é utilizado quando as línguas expressam os mesmos significados "através de meios estilísticos e estruturais totalmente diversos" (BARBOSA, 1990, p.29), como por exemplo, quando é necessário traduzir o "repertório fraseológico, idiotismos, clichês, provérbios, interjeições e onomatopéias". Pois estas expressões que podem apresentar significados literais ou metafóricos

encerram uma mensagem total em si mesmas [...] já que os povos criaram provérbios cujo referencial se encontra em sua realidade extralingüística particular que, muitas vezes, será incompreensível para falantes de outras línguas, os quais terão gerado seus provérbios particulares, baseados em sua própria realidade extralingüística. (BARBOSA, 1990, p. 29)

Nida (1964, apud BARBOSA, 1990, p. 34), outro tradutólogo que também propõe a técnica da equivalência, afirma que pode ser de dois tipos: a formal e a dinâmica. De acordo com a primeira, o texto traduzido deve manter-se fiel aos diversos elementos linguísticos e extralinguísticos. Ao contrário, a segunda:

tem como meta atingir uma total naturalidade na expressão da MENSAGEM1, o TO [texto original], na LT [língua da tradução] e tenta transpor o TLO [texto na língua original] para a LT de tal modo que o leitor encontre no TLT [texto língua da tradução] modos de comportamento e outros elementos extralingüísticos relevantes em sua própria cultura; não insiste em que ele compreenda padrões culturais do contexto da LO a fim de poder compreender a mensagem. 
O tradutor, portanto, deve buscar o princípio do efeito equivalente propondo equivalências semânticas para expressar os mesmos significados e equivalências pragmáticas que respeitem os mesmos registros sociolinguísticos: culto, coloquial, popular, familiar e níveis de formalidade ou informalidade.

Ultimamente, vários teóricos (HURTADO ALBIR, 1988; CERVO, 2005; RIDD, 2003; WELKER, 2003) entre outros e, consequentemente, alguns professores estão tentando promover uma reconciliação limitada e condicionada entre a tradução e o ensino de línguas, baseando-se, fundamentalmente, em uma concepção da tradução como processo de re-expressão do sentido e não das palavras, assim como o lugar que a língua materna deve ocupar no processo de aprendizagem de uma língua estrangeira. Hurtado Albir (1988, p. 42) comenta que

o recurso à "tradução" no ensino de línguas abarca dois aspectos bem diferenciados. Trata-se, por um lado, da tradução de textos, seja para a língua materna do aluno (a "tradução direta"), considerada como a verdadeira tradução por possuir um domínio perfeito da língua de chegada, ou para a língua estrangeira no processo de aprendizagem (a "tradução inversa"), neste caso o espanhol. Por otro lado, a tradução pode intervir também no ensino de línguas como mecanismo de acesso ao significado da língua estrangeira, seja de um modo "silencioso" e interiorizado, seja de maneira mais explícita recorrendo al dicionário biligue ou a uma "tradução explicativa" do professor." (Grifos do autor)

Como estratégia para ensinar as expressões idiomáticas, defendida por Lima (1998a, 1998b), sugerimos o critério de

\footnotetext{
${ }^{5}$ El recurso a la "traducción" en la enseñanza de lenguas abarca dos aspectos bien diferenciados. Se trata, por un lado, de la traducción de textos, sea para la lengua materna del alumno (la "traducción directa"), considerada como la verdadera traducción por poseerse un dominio perfecto de la lengua de llegada, o para la lengua extranjera en proceso de aprendizaje (la "traducción inversa"), en este caso el español. Por otro lado, la traducción puede intervir también en la enseñanza de lenguas como mecanismo de acceso al significado de la lengua extranjera, o bien de un modo "silencioso" e interiorizado, o bien de manera mas explícita recurrindo al dicionário biligüe o a una "traducción explicativa" del profesor.
} 
apresentação, segundo as equivalências semântico-pragmáticas, ou seja, ao apresentar as expressões idiomáticas aos alunos, podemos introduzir também as equivalências em língua portuguesa. Nesse caso, optamos pela "tradução explicativa", ou seja, apresentamos ao mesmo tempo a expressão em espanhol e em português, sempre usando-as dentro de um contexto, para que os alunos possam internalizar os significados metafóricos. Acreditamos que esta estratégia facilita a memorização e o uso adequado contextualmente, porque saber que determinada expressão em espanhol equivale semântica e pragmaticamente a uma determinada expressão em português pode ajudar a selecionar a que se adequa ao contexto. Com certeza, muitos professores já tiveram a oportunidade de presenciar em determinados momentos na sala de aula, alguns alunos utilizando a tradução para encontrar as equivalências de palavras, estruturas e expressões do espanhol ao português. Poderíamos pensar que usando métodos comunicativos este tipo de atitude não deveria ocorrer, porém estaríamos equivocados, segundo Hurtado Albir (1988, p. 42):

presença da língua materna tambem é um aspecto positivo se considerarmos que o alumno ao adquirir sua língua materna aprendeu a se comunicar, o que significa que possui toda uma experiência linguística e cognitiva prévia que é preciso saber aproveitar no ensino de uma língua estrangeira ${ }^{6}$.

\section{Implicações para a compreensão das expressões idiomáticas}

Se queremos alunos comunicativamente preparados para compreender e se expressar adequadamente em E/LE, precisamos oferecer-lhes as ferramentas necessárias para que desenvolvam a competência sociolinguística, este é o nosso objetivo diário, em cada aula ministrada. Portanto, ao ensinar compreensão de leitura,

\footnotetext{
${ }^{6}$ La presencia de la lengua materna también es un aspecto positivo si consideramos que el alumno al adquirir su lengua materna aprendió comunicarse, lo que significa que posee toda una experiencia lingüística y cognitiva previa que hay que saber aprovechar la enseñanza de una lengua extranjera.
} 
trabalhamos com os textos com duas finalidades: leitura como meio e como fim (ARGÜELLES, 1998).

Reconhecemos a importância da leitura como fim em si mesma, ou seja, como um veículo para adquirir conhecimento e informação, prazer, lazer, e como um meio que possa ajudar os alunos a reconhecerem e a usar as estratégias cognitivas e metacognitivas, desenvolvendo a autonomia de cada um. Podemos ajudar-lhes, também, a ativar os conhecimentos que já têm do tema a partir do contexto e que podem ser apresentados através dos elementos verbais ou não verbais, das predições e inferências, ou como fazer uso de seus conhecimentos prévios sobre o tema. Com base nas postulações de Koch (1997) sobre a análise das estratégias cognitivas efetuadas pelos interlocutores (leitor - texto - autor), compreendidas como aquelas que dizem respeito ao uso dos conhecimentos do mundo (frames, esquemas, planos e scripts) e compartilhado, do contexto sociocultural e das inferências, concluímos que os alunos precisam ativar esses conhecimentos para poder interpretar os textos.

Assim, os conhecimentos sociocultural e de mundo, que devem ser ativados durante a leitura, referem-se aos esquemas e aos costumes de um povo, os que, normalmente, ditam as regras de comportamento e as ações. Portanto, "o esquema é o conhecimento parcial estruturado que temos na memória sobre assuntos, situações típicas de nossa cultura", segundo Kleiman (2000, p. 23). Marcuschi (1996, p. 65) define a comprensão textual de maneira que inclui a interpretação, pois para este autor "compreender um texto envolve muito mais do que somente o simples conhecimento da língua e da reprodução de informações". Por isso, a compreensão passa a ser um "processo criador, ativo e construtivo que vai muito além da informação estritamente textual".

Tradicionalmente, o nível coloquial em língua espanhola se caracteriza pelo usogde uma grande variedade de expressões figuradas. Como nos explica Sánchez Lobato (1999, p. 25), “o adagiário popular está repleto de expressões, de formas de vida, de ditados que revelam a presença da cultura religiosa entre o povo"7, e podemos acrescentar outras que se relacionam com vários campos léxicos e semânticos

\footnotetext{
${ }^{7}$ El adagiario popular está repleto de expresiones, de formas de vida, de dicho que revelan la presencia de la cultura religiosa entre el pueblo.
} 
como, por exemplo, festas populares, (tauromaquia etc.), urbanidade (léxico marginal: droga, prostituição, mundo carcerário), ciganismos, coloquialismos, léxico do esporte, da medicina, da construção, comidas, cores, tempo, partes do corpo etc. Consequentemente, "a linguagem, pois, responde a uma sociedade permeável na qual o léxico reflete a condição de vida do falante, sua base cultural e seu nível social e político" (SÁNCHEZ LOBATO, 1999, p. 25).

Com relação ao ensino de expressões idiomáticas, Higueras (1997, p. 15) ao apresentar as vantagens, necessidade e utilidade de ensiná-las, comenta que:

não podemos esquecer o inegável legado cultural que se aprende com as expressões idiomáticas: este pode ser um bom ponto de partida para explicar comportamentos, atitudes, formas de vida, modos de pensar [...] e promover assim una aprendizagem intercultural ${ }^{9}$.

Em El componente idiomático en la lectura en E/LE (LIMA, 2005), descreve-se a realização de uma das atividades propostas por Higueras (1997, p. 17), baseada na dedução dos significados apresentados no contexto. Posto que "conviene que los modismos sean inseridos en un texto amplio para que sea más facil comprender su significado", segundo esta última autora.

\section{Considerações finais}

A título de conclusão, como já dissemos, a língua é uma manifestação cultural que adquirimos simultaneamente com a língua que estudamos. Portanto, a realidade que uma língua atualiza de uma maneira, em outra pode configurar-se de uma maneira distinta. Um claro exemplo disso são as expressões idiomáticas que tratamos de discutir.

\footnotetext{
${ }^{8}$ El lenguaje, pues, responde a una sociedad permeable en la cual el léxico refleja la condición de vida del hablante, su base cultural y su nível social y político.

${ }^{9}$ No podemos olvidar el inegable legado cultural que se aprende de los modismos: este puede ser un buen punto de partida para explicar comportamientos, actitudes, formas de vida, modos de pensar [...] y promover así un aprendizaje intercultural.
} 
Constatamos, em muitos casos, que temos nas duas línguas a mesma estrutura ou correspondência formal para atualizar a mesma realidade, porém em outros não há correspondências formais, embora em outros casos encontremos correspondências semânticopragmáticas. Parece claro que as interpretações culturais são adquiridas juntamente com a língua. Entender uma mensagem significa conceitualizá-la e essa conceitualização significa entender, compreender e ser capaz de codificá-la e descodificá-la.

$\mathrm{O}$ aluno e o tradutor têm que entender o texto, para isso devem ter ótimos conhecimentos linguísticos e extra-linguísticos ou o conhecimento da língua, e é conveniente conhecer o tema da matéria que trata o texto, porque se o desconhecemos, podemos perder alguns detalhes e pode ocorrer que não saibamos encontrar as designações para atualizá-los adequadamente. Esta postura é defendida também por Hurtado Albir (1988, p. 43) quando afirma que

assim adotamos uma postura comunicativa e consideramos que o que se traduz sempre é o sentido produzido a partir da confluência dos elementos linguísticos que intervém na comunicação (conhecimento da situação, do tema, dos códigos socioculturais, etc), assim o que faremos é buscar o modo de transmitir esse sentido produzindo um efeito equivalente no destinatário da outra língua. Porém para que seja possível a conceptualização da mensagem é imprescindível conhecer a língua. ${ }^{10}$

Vemos que os problemas da tradução são manifestações concernentes aos mesmos problemas da comunicação, e podemos tratar de resolvê-los usando princípios comunicativos básicos da pragmática. A tradução das expressões idiomáticas espanholas e brasileiras desde nosso ponto de vista, é uma das dificuldades mais

\footnotetext{
${ }^{10}$ Así adoptamos una postura comunicativa y consideramos que lo que se traduce siempre es el sentido producido a partir de la confluencia de los elementos lingüísticos que intervienen en la comunicación (conocimiento de la situación, del tema, de los códigos socioculturales, etc), así lo que haremos es buscar el modo de transmitir ese sentido produciendo un efecto equivalente en el destinatario de la otra lengua. Pero para que sea posible la conceptualizavión del mensaje es imprescindible conocer la lengua.
} 
frequentes que encontramos no processo de ensino/aprendizagem de E/LE.

As estratégias que apresentamos ao longo do texto são algumas sugestões dentre as várias maneiras de classificar ou agrupar as expressões idiomáticas. Certamente, cada professor dentro de sua realidade tem condições de apresentar outras possibilidades de trabalho que sejam muito mais práticas e adequadas. Tentamos apresentar a importância das expressões idiomáticas no processo de ensino e aprendizagem, pois elas encerram em si fatos linguísticos e extralinguísticos.

Chegamos à conclusão de que o trabalho do professor de línguas estrangeiras é muito similar ao do tradutor, pois tem a mesma base que é a língua. Fazemos nossas as palavras do filósofo espanhol Ortega e Gasset (1983, p. 435) para afirmar que "o assunto da tradução, por pouco que o persigamos nos leva até os arcanos mais recônditos do maravilhoso fenômeno que é a fala"11.

Este tipo de atividade de leitura e de tradução é interativa, pois exige que os alunos interajam com o autor do texto e os colegas para que possam construir uma leitura significativa. É preciso superar a leitura superficial e mergulhar no texto, encontrando as respostas que estão nas entrelinhas. Ademais é necessário fazer inferências e começar a olhar o texto como um lugar de encontro onde se necessita uma atitude ativa para perceber o discurso como uma trama linguística constituída socioculturalmente.

Acreditamos que é o conjunto de competências linguística, sociolinguística, sociocultural, estratégica, discursiva e intercultural que pode assegurar a instauração de uma prática de leitura para a interpretação crítica de um texto, tanto em língua materna como em línguas estrangeiras, pois ao aproximarmos de um texto escrito é como se estivéssemos aproximando-nos de alguém para dialogar e negociar os significados com nosso interloculor, em um processo comunicativo, no qual são necessárias ditas competências para que a comunicação possa ser estabelecida efetivamente.

Como conclusão, podemos afirmar que este tipo de prática de leitura, como uma interação entre os interlocutores, pode nos ajudar a

\footnotetext{
11 Tradução nossa: “e asunto de la traducción, por poco que lo persigamos nos lleva hasta los arcanos más recónditos del maravilloso fenómeno que es el habla”.
} 
perceber que as atividades e estratégias (cognitivas e metacognitivas) de leitura têm um papel relevante no desenvolvimento da competência comunicativa, considerando os processos de leitura como meio ou como fim em si mesma. Reconhecer as pistas contextuais para chegar às inferências é imprescindiível em uma prática de leitura interativa. É muito proveitosa e relevante a realização desse tipo de atividades porque, apesar do esfoço para fazer as inferências adequadas, temos a oportunidade de ampliar os conhecimentos socioculturais dos alunos em relação ao uso das expressões idiomáticas características em uma conversação coloquial em espanhol. Consideramos, como Sánchez Lobato (1999, p. 26), que "aprender uma língua significa aprender parte da cultura na qual ocourreu, ocorre e ocorrerá um grande número de situações culturais" $"$.

\section{Referências}

ARGÜELLES, Irina. La lectura en L2 ¿Un medio o un fin? Frecuencia L, n. 8, Madrid: Edinumen, p. 34-37, 1998.

BARBOSA, Heloísa. Gonçalves. Procedimentos técnicos da tradução. Campinas, SP: Pontes, 1990.

CASARES, Julio. Introducción a la lexicografía moderna. Madrid: CSIC, 1992.

CERVO, Irène Zohra Sérèro. Tradução pedagógica: enfoques linguístico e interpretativo. Horizontes de Linguística Aplicada, ano 4, n. 1. Brasília, p. 67-78, 2005.

GIOVANNINI, Arno. MARTIN PERIS, Ernesto. RODRÍGUEZ, María. SIMÓN, Terencio. Profesor en acción 3: destrezas. Madrid: Edelsa, 1996. p. 23-46.

\footnotetext{
12 Tradução nossa: "aprender una lengua significa aprender parte de la cultura en la cual ocurrió, ocurre y ocurrirá un gran número de situaciones culturales”.
} 
HIGUERAS, Marta. La importancia del componente idiomático en la enseñanza del léxico a extranjeros. Frecuencia L, n. 6, Madrid: Edinumen, p.15-19, 1997.

HURTADO ALBIR, Amparo. La traducción en la enseñanza comunicativa. Revista Cable, v. 1, Madrid: Equipo Cable, abril de 1988, p. 42-45.

KLEIMAN, Angela. Oficina de leitura: teoria e prática. 7 ed. Campinas, SP: Pontes, 2000.

KOCH, Ingedore Grunfeld Villaça. V. O texto e a construção dos sentidos. São Paulo: Contexto, 1997.

LARAIA, Roque Barros. Cultura: um conceito antropológico. Rio de Janeiro, Jorge Zahar Editor, 1993.

LIMA, Lucielena Mendonça. El componente idiomático en la lectura en E/LE. Actas del XII Seminario de Dificultades Específicas de la Enseñanza del Español a Lusohablantes. Brasilia: Consejería de Educación y Ciencia de la Embajada de España en Brasil, Ministerio de Educación y Ciencia de España, 2005. p. 209-220.

. La traducción de los modismos en la enseñanza del español como lengua extranjera. In: MORENO FERNÁNDEZ, Francisco; GIL, María; ALONSO, Kira. (Eds.). Actas del VIII Congreso Internacional de ASELE: El Español como Lengua Extranjera: del Pasado al Futuro, Alcalá de Henares: Servicio de Publicaciones de la Universidad de Alcalá, 1998a, p.570-584.

Descripción de las equivalencias semánticas entre modismos españoles y brasileños. Tese (Doctorado). Universidad de Oviedo, España. 1998b. Inédita.

MARCO, José. Literatura popular en España en los siglos XVIII y XIX, Tomo I. Madrid: Taurus, 1977. 
MARCUSCHI, Luis Antonio. Exercícios de compreensão ou copiação nos manuais de ensino de língua? Em Aberto, v. 69, p. 64-82, 1996.

McCARTHY, Michael.; O’DELL, Felicity. English vocabulary in use. Cambridge: Cambridge University Press, 1994.

NIDA, Eugene, A. Linguistics and ethnology problems. Words, v. 2, p.194-208, Londres. 1964.

ORTEGA Y GASSET, José. Miseria y esplendor de la traducción. Obras completas, v. V. Madrid. Revista de Occidente, p. 443-451, 1983.

RIDD, Mark David. Um casamento estranhamente ideal? A compatibilidade de gênios entre o comunicativo e a tradução. Horizontes de Lingüística Aplicada, a. 2, n.1, p. 92-104, 2003.

SANCHEZ LOBATO, Jesús. Lengua y cultura: la tradición cultural hispánica. Carabela, v. 45, Madrid: SGEL, p. 5-26, 1999.

TAGNIN, Stella Esther. O. O jeito que a gente diz. São Paulo: Disal, 2005.

VARELA, Fernando; KUBARTH, Hugo. Diccionario fraseológico del español moderno. Madrid: Gredos, 1996.

VÁZQUEZ-AYORA, Geraldo. Introducción a la Traductología: curso básico de traducción. Washington: Georgetown University Press, 1977.

WELKER, Herbert Andreas. Traduzir frases isoladas na aula de língua estrangeira: por que não? Horizontes de Lingüística Aplicada, a. 2, n.2, p. 149-162, 2003.

VINAY, Jean Paul; DARBELNET, Jean. Stylistic comparée du français et de l'anglais: methode de traduction. Paris; Didier, 1957. 
Lucielena M. Lima e Maria Luisa Ortiz Álvarez

XATARA, Cláudia Maria. O ensino do léxico: as expressões idiomáticas. Trabalhos em Lingüística Aplicada, Campinas, v. 37, p. 49-59, 2001.

Recebido em: 08/06/2011 Aceito em: $\quad$ 08/12/2011

Title: The teaching of Spanish idioms and their equivalents in Portuguese 
O ensino das expressões idiomáticas em língua espanhola 